Transforming the energy system

\title{
Digitalizing the Energy System in a Sustainable Way
}

\author{
The energy transition requires a restructuring of \\ the energy system and, as a result of decentra- \\ lisation, also increasing digitalisation to integrate \\ all actors and make them more flexible. However, \\ digitalisation can be shaped and should happen \\ under ecological and social premises. \\ By Swantje Gährs, Astrid Aretz, Friederike Rohde \\ and Hendrik Zimmermann
}

G ermany has set itself the goal of making its entire electricity supply greenhouse gas neutral by 2050 and reducing its energy demand by $50 \%$. Both goals together form the basis of a sustainable energy supply. The share of renewable energies in the German electricity mix is currently $42.1 \%$ of gross electricity consumption (UBA 2020), which poses challenges for grid operation at both distribution and transmission grid level. This is because the availability of energy is no longer constant but fluctuating. Many small, spatially distributed generation units create the need for greater flexibility in the energy system. This energy transition is associated with a growing number of actors that are participating in the energy system for example by generating their own electricity or heat with photovoltaic systems, wind turbines or heat pumps, and in some cases also feeding it into the grids. This decentralisation and diversity of actors, however, also increases the complexity of the energy system and thus the requirements to coordinate actors and regulate market and grid activities. For a supply with almost $100 \%$ renewable energies to be possible at all, the energy must be balanced intelligently. The opportunities offered by ICT-devices, big data, machine learning as well as the business models based on them, are envisioned as an important step towards a successful energy transition (dena 2016). There is need for more and more information on grid conditions and operations, as additional storage facilities have to be integrated into the electricity system and the coupling with other sectors such as mobility and heat needs to be coordinated. The overarching vision is that digital technologies will enable energy flows to be measured, controlled and traded in real time. However, the physical changes in the energy system also require new forms of coordination (e.g., electricity market design) and new regulatory frameworks. This vision is thus strongly interrelated with political strategies and regulatory processes (e.g., the Climate Protection Plan 2050 or the Act on the Digitalisation of the Energy Transition), actors on the market who endeavour to open up new business areas or automate and flexibilise processes (cf. e. g., Maier 2018, Lied 2017), and also a strong civil society that not only accepts the changes but also promotes them through political pressure and new ideas and cooperation.

\section{Flexible consumers and new forms of coordination}

The Renewable Energy Sources Act (EEG) provides the opportunity for consumers to participate actively in the electricity market as producers of renewable electricity. Initially, the role of these so-called prosumers was limited to generating the electricity and feeding it completely into the grid. However, the self-consumption of self-generated electricity has significantly increased the scope for action. Consumers themselves could control the times at which they switch on electrical appliances in their household and thereby help to regulate their own consumption in a way that is more economical than feeding the electricity into the grid. Automatic controls and electricity storage have increased this scope even further. Digitalisation can create new forms of organisation and additional flexibility options from individual actors at household level through their networking and aggregation at district level. Developments such as local self-consumption (peer-to-peer or community electricity trading) as well as local or regional electricity markets, in which operators sell their surplus electricity directly to other consumers, are currently difficult to realise due to the regulatory condition. However, their implementation has already been successfully demonstrated in pilot projects.

These developments strengthen the role of consumers in the energy market. This is in line with the targets of the EU's Clean Energy Package, which are to be implemented in national law by all EU member states by the end of 2020 (European Parliament 2019). At the same time, it enables consumers to provide flexibility that can contribute to stabilising the electricity system. It makes sense for larger electricity consumers in particular to manage their own consumption and adjust it to market signals. This flexibilization must be supported more strongly. Additional storage facilities, such as those provided by electromobility, would significantly increase this potential. However, this requires enormous coordination efforts between 


\section{HOW TO CREATE A DIGITAL ENERGY SYSTEM IN A SUSTAINABLE WAY}

A sustainable energy system has to be developed in an ecological, resilient and inclusive way that is open to diverse technologies. This must be ensured by appropriate market designs, regulative regimes and technical standards. These rules simultaneously have to ensure the coordination of all actors in the energy system.

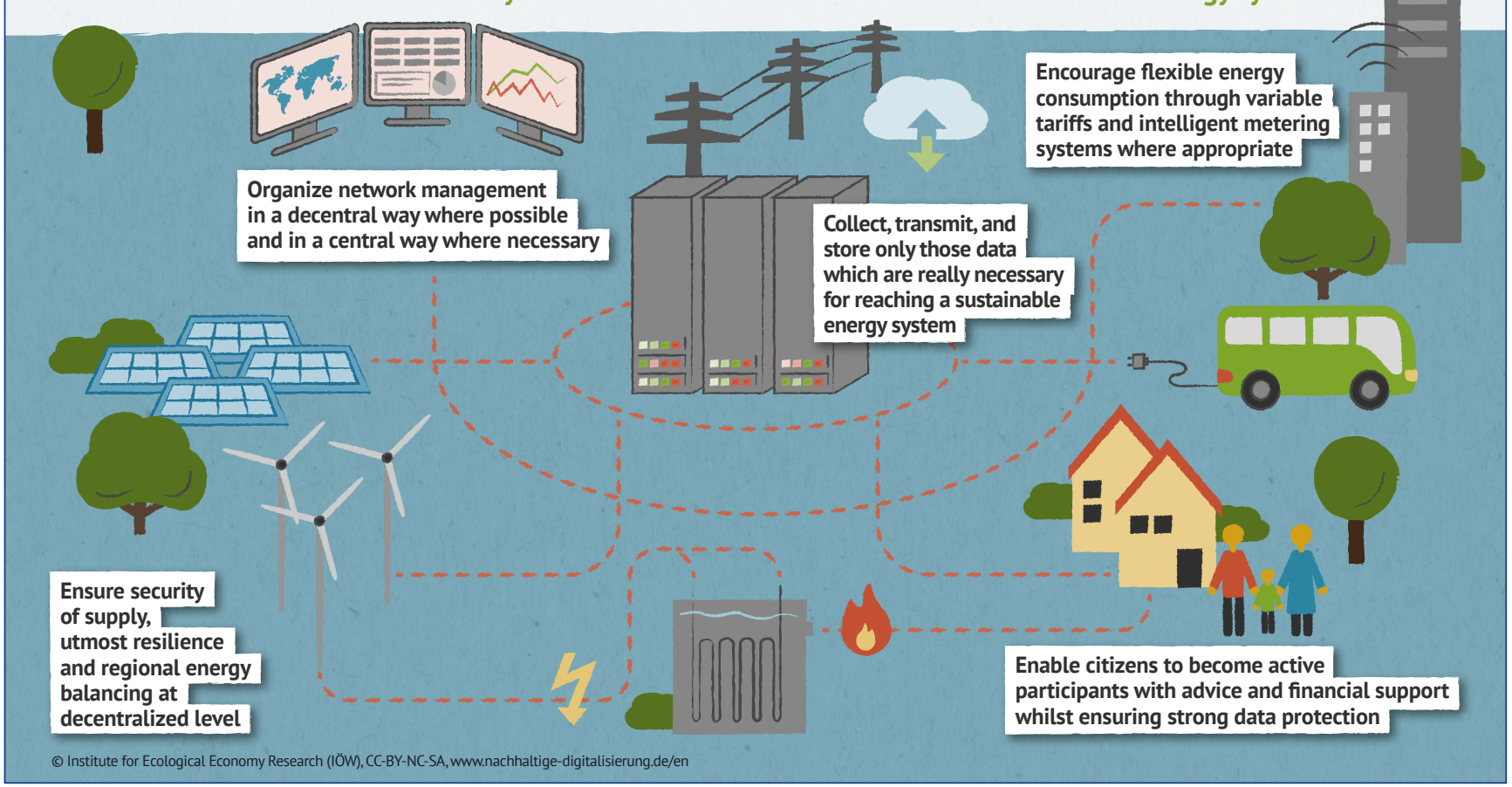

Figure 1: How to create a digital energy system in a sustainable way

the actors in the energy system, which cannot only be facilitated by digital solutions, but also requires changes on different levels such as a new electricity market design and decentralised organisation (see Figure 1).

\section{Digitalised grid control in the smart grid}

The increased complexity in the energy system resulting from distributed and fluctuating energy supply is making it more and more challenging to balance the supply and demand of energy within the distribution and transmission grids. The risk of unstable grid conditions increases. Intelligent electricity grids (smart grids) are intended to help overcome this complexity and ensure the stability of the electricity grids. A smart grid transports not only energy, but also data that enables grid operators to obtain information on electricity production, transport, storage, and consumption at short intervals. For example, they are able to know exactly when and where a decentralised generation plant feeds electricity into the grid. The greater availability of data through sensor technology (in particular through smart metering systems) allows grid operators to better record their grid and, if actuators are available, also to intervene in a controlling manner. This means that a stable grid situation can be ensured at all times, even with a high proportion of decentralised electricity generation, and existing grids can be utilised to a greater extent (Expertengruppe Intelligente Energienetze 2019).

However, significant challenges are remaining with regard to smart grids that have not yet been addressed in a reasonable way. For instance, there are rules that allow grid operators to switch off individual producers or consumers in the event of grid bottlenecks, in order to avoid a power blackout. It remains unclear though, which economic and technical criteria should be used to select the shutdowns in a complex context from a multitude of options. This is where algorithms and digital tools should provide support. It is also true that, in principle, the responsibility between distribution system operators and transmission system operators has been clarified according to grid levels in the current energy system. But the changing roles when there are multi-layered interactions between these levels are still being negotiated. It is also unclear how access to the collected data is organised and which platforms are suitable for this. 


\section{"The fundamental transformation of the electricity system opens up the possibility of integrating resilience strategies and promoting social balance."}

\section{The material foundation of smart energy systems}

Reducing absolute energy consumption is imperative for achieving climate protection goals. Only a reduction of $50 \%$ by 2050 makes a complete switch to renewable energies "at all realistic” (Prognos/Öko-Institut/Wuppertal-Institut 2020). But do the resources, data flows and possibly additional energy requirements necessary for digitalisation justify the savings that can be achieved as a result? Especially the production of digital devices requires some energy. For example, according to our own calculations based on Sias (2017), the production of an advanced metering system (iMS) (without smart meter gateway) produces $91 \mathrm{~kg}$ of $\mathrm{CO}_{2}$ equivalents, while a Ferraris meter comes in at around $8 \mathrm{~kg}$ of $\mathrm{CO}_{2}$ equivalents. The power consumption in operation is also somewhat higher with an iMS including the smart meter gateway. A comprehensive assessment of the environmental impact also requires consideration of the lifetime, energy consumption of data centres and production conditions (see Pohl et al. this issue).

The consumption of energy and resources must now be contrasted with the positive effects of digital technologies. These are to be expected first and foremost where digital technology has been installed and may relate to expected efficiency gains. For example, electricity savings when using a weather forecast control system in a multi-family house range between 4 and $20 \%$ annually (Hengstenberg 2018; Oschatz/Mailach 2017) and between 2.5 and $5 \%$ when using online efficiency monitoring (Hermann et al. 2019). However, the expected efficiency gains can be overcompensated if additional digital devices are acquired.

Particularly in the electricity sector, digitalisation often aims at positive effects on a higher level. An important level of impact, however, is in grid control, which should enable better utilisation of the electricity grids through knowledge of grid conditions and energy demand, while at the same time increasing the share of renewable energies. A similar systemic effect is expected for remotely controllable loads such as heat pumps. The expectation for the control of flexible loads is that digitally coordinated load shifting will have a positive effect on the grids on the one hand, whilst on the other hand reducing renewable energy curtailment.

The intended effects of a digitalised energy system can therefore be very diverse. At the same time, they are still very uncertain in many places. Nevertheless, initial studies indicate that in the area of smart energy systems, the savings achieved are greater than the negative environmental impacts caused by the production and operation of sensor technology, measuring devices and ICT and the data transfer (Ipsen et al. 2019).

\section{New vulnerabilities}

Future life and economic activities with a growing number of electrical and electronic devices depend to a large extent on a stable and reliable power supply. Digitalised electricity grids harbour risks for cyberattacks that can endanger security of supply. This increases the system's vulnerability. Against the background of such potentially catastrophic, economically and socially hardly sustainable consequences, the question of the vulnerability and resilience of the power supply system is of central importance.

The fundamental transformation of the electricity system that is currently underway opens up the possibility of integrating resilience strategies into the design of the electricity system. A major focus here is on the granularity of the system architecture. This refers to the size of the smallest network element of the power supply that is to be stabilised. Whether granular systems are inherently more resilient is currently a matter of debate among experts (e.g., Hirschl et al. 2018). There is agreement that central systems can have different vulnerabilities than decentralised systems: Central components are highly vulnerable because their failure can have far-reaching consequences for system stability, whereas smaller components in a decentralised system do not have such far-reaching consequences. On the other hand, vulnerability is seen in the large number of similar system components (such as parts, software, protocols and standards) that may be less well secured or maintained and therefore represent a target for attack in their entirety. Diversification of system components and software is therefore seen as a strategy to reduce vulnerability (acatech 2017). In this context, the use of open standards and opensource software is also discussed (Pohl et al. 2020). Likewise, the provision of redundancies is an important additional measure to ensure security of supply. This does, however, go hand in hand with increased resource requirements. The topics of IT security, data protection and data security are also important in a digitalised energy system. In Germany, the Cybersecurity Act regulates how metering point operators must protect their systems from manipulation and unauthorised access. From the consumers' perspective, better data protection could be ensured through clearer T \& Cs with privacy-by-design and privacy-by-default and through a strict e-privacy regulation. 


\section{Social aspects of a digitalised energy system}

The social aspects of a digitalised energy system are evident at various levels. Digitalisation initially has an impact on the costs for consumers. Intelligent grid control can, for example, reduce the costs of grid operation and thus the grid charges by contributing to grid stabilisation. Since grid charges account for a large share of electricity prices and electricity prices have a regressive effect, equipping the grids from medium to extra-high voltage with sensors and actuators is particularly worthwhile.

The digitalisation of grid operations can also promote social balance: For example, a calculation algorithm that keeps transaction costs low could enable a favourable horizontal equitable distribution of grid charges. This can provide financial relief for people in rural areas (with few grid connections in the neighbourhood) or in regions with a high share of renewable energies in electricity generation (and resulting strong fluctuations in grid status).

The use of smart meters in low voltage also has the potential to reduce overall system costs in the long term and consequently also costs for socially disadvantaged people (Faruqui et al. 2010). Smart meters are currently most profitable for people with energy technologies such as solar systems, home storage or electric cars, or with particularly high electricity consumption, which is why the costs of these consumption groups are reduced more in relative terms. From a social point of view, the costs of smart meters for households with low consumption should therefore be (partly) financed by the state. Smart meters should enable and incentivise flexibility through sufficient sensor and actuator technology, and exploit the physical potential of flexibility. This requires variable price signals on the market side, which can be implemented, for example, by means of variable grid charges. Smart meters can enable consumers to regulate their electricity consumption in a more cost-oriented way. So-called pre-payment meters (P PM) with an advance payment function can, for example, help to relieve the burden on companies' payment arrears departments (Kopatz 2012). These are currently used mainly by the socially disadvantaged and frequently part of the charge is used to pay off debts. This is to prevent the socially disadvantaged from getting (further) into debt. However, especially in energy-poor households, energy saving potentials are low. Debt repayment and electricity consumption are usually not perceived separately, which is counterproductive to improved control of one's own consumption (Berger 2017). As P PMs shift the responsibility for supply to consumers, so-called "self-disconnections" can occur in financial emergencies (Coutard/Guy 2007). Where previously humans could exercise leniency, technology then decides without empathy (Ingram et al. 2007). In addition to lighting, however, refrigerators, cooking facilities or the internet are also turned off. A lack of electricity and light can be noticed in the neighbourhood and result in stigmatisation. The subsequent costs are often borne by society (Reibling/Jutz 2017). The use of PPMs should therefore be opposed from a social point of view.
Beyond this cost issue, digitalisation enables the integration of decentralised renewable energy systems and consequently often also the participation of members of the public in the energy supply. Digital technologies facilitate new supply structures that enable everyone to participate, if not as a producer, then at least as a consumer. However, to ensure that not only house- or landowners benefit, the framework conditions for tenant electricity must be significantly improved. Other promising models that could become increasingly important in the future are communal self-sufficiency or peer-to-peer trading. This strengthens the role of members of the public. At the same time, it opens up the opportunity to increase participation in the energy system and acceptance for the transformation requirements of the energy system (e. g., expansion of renewable energies).

\section{Political governance ...}

The digitalisation of the energy system brings new challenges in terms of political governance. The complexity of control in the interplay between highly regulated grid operation and a liberalised energy market is increasing.

Important regulatory foundations were laid with the White Paper An Electricity Market for Germany's Energy Transition (BMWi 2015), the Act on the Digitalisation of the Energy Transition (BMWi 2016) and the Green Paper on Energy Efficiency (BMWi 2017) resulting from consultation processes at the German Federal Ministry for Economic Affairs and Energy (BMWi). Significant challenges at regulatory level exist in the areas of digital metering, flexibility of end consumers and the creation of framework conditions for new business models (e.g. flexible tariffs). For instance, during the smart meter rollout it became apparent that there were initially no devices on the market that met the high security requirements of the Federal Office for Information Security (BSI). Progress has since been made here, for example in that the question of who may access which data from smart metering systems, and when, will in future become part of the principle of point-to-multipoint communication. It involves processing the metering data in the smart meter gateway and making it directly available to the relevant actors using end-to-end encryption.

\section{... between energy market and grid regulation}

Furthermore, there are still many unresolved legal issues in the area of flexibilization of the consumption side, which are currently being discussed in the context of a revision of Section 14a EnWG. This concerns in particular questions of the design of grid-friendly flexibility. However, there must not be too much emphasis on small, private consumers and the focus must be on regions with a strong expansion of renewable energy. There are also open questions concerning the regulations of storage facilities as consumption facilities and the harmonisation of the Renewable Energy Sources Act (EEG) with the Me- 


\section{"The digitalisation of the energy system brings new challenges in terms of political governance."}

tering Point Operation Act (MsbG), which are currently being worked on (Ernst \& Young 2020).

The future challenge for the digitalisation of the energy system is to bring policymaking in line with technical developments, whilst keeping in mind not only the security of supply, reliability and affordability of the energy supply, but also climate and resource protection, data protection and social justice. These sustainability aspects should be at the centre of the design of a digitalised energy system.

\section{References}

acatech (2017): Das Energiesystem resilient gestalten: Maßnahmen für eine gesicherte Versorgung. www.acatech.de/publikation/das-energiesystemresilient-gestalten-massnahmen-fuer-eine-gesicherte-versorgung/

Berger, T. (2017): Energie prepaid. Sozio-technische Implikationen im Management energiearmer KonsumentInnen durch Prepayment-Meter. In: Großmann, K./Schaffrin, A./Smigiel, C. (Eds.): Energie und soziale Ungleichheit. Wiesbaden, Springer. 403-424.

BMWi (2015): An electricity market for Germany's energy transition. Berlin, Federal Ministry for Economic Affairs and Energy.

BMWi (2016): Gesetz zur Digitalisierung der Energiewende. www.bmwi. de/Redaktion/DE/Downloads/Gesetz/gesetz-zur-digitalisierung-derenergiewende.html

BMWi (2017): Green Paper on Energy Efficiency: Evaluation report on the public consultation. Berlin, Federal Ministry for Economic Affairs and Energy.

Coutard, O./Guy, S. (2007): STS and the City Politics and Practices of Hope. In: Science, Technology, \& Human Values 32/6: 713-734.

dena (2016): Grundsatzpapier der Plattform Digitale Energiewelt. www.dena. de/newsroom/publikationsdetailansicht/pub/grundsatzpapier-derplattform-digitale-energiewelt/

Ernst \& Young (2020): Barometer Digitalisierung der Energiewende. www.bmwi.de/Redaktion/DE/Publikationen/Studien/barometerdigitalisierung-der-energiewende-berichtsjahr-2019.html

European Parliament (2019): Regulation (EU) 2019/943 of the European Parliament and of the Council of 5 June 2019 on the internal market for electricity. https://eur-lex.europa.eu/legal-content/EN/ TXT/?uri=CELEX\%3A32019R0943

Expertengruppe Intelligente Energienetze (2019): Nutzen und Anwendungen Intelligenter Energienetze. Berlin, Expertengruppe Intelligente Energienetze.

Faruqui, A./Sergici, S./Sharif, A. (2010): The impact of informational feedback on energy consumption - A survey of the experimental evidence. In: Energy 35/4: 1598-1608.
Hengstenberg, J. (2018): Die vorausschauende Steuerung von Heizanlagen Vortrag von Johannes Hengstenberg. www.senercon.de/2018/10/02/ video-vortrag-zum-thema-vorausschauende-steuerung-von-heizanlagen/

Hermann, L./Hennig, P./Metzger, S./Köhrer, M./Pauser, L./Yanev, D./ Homburg, A./Knauff, M. (2019): Energiemonitoring und Informationsaustausch bei Geräten und Anlagen (Zählerstudie). Final Report. Berlin, BAFA/BMWi/UBA.

Hirschl, B./Aretz, A./Bost, M./Tapia, M./Gößling-Reisemann, S. (2018): IKT und Stromversorgung: Potenziale und Risiken der Kopplung in Bezug auf Vulnerabilität und Resilienz. Final Report. Berlin, Bremen.

Ingrim, J./Shove, E./Watson, M. (2007): Products and Practices: Selected Concepts from Science and Technology Studies and from Social Theories of Consumption and Practice. In: Design Issues 23/2: 3-16.

Ipsen, K. L./Zimmermann, R. K./Nielsen, P. S./Birkved, M. (2019). Environmental assessment of Smart City Solutions using a coupled urban metabolism - life cycle impact assessment approach. In: The International Journal of Life Cycle Assessment 24/7: 1239-1253.

Kopatz, M. (2012): Energiearmut lindern: Prepaid statt Sperre. In: Energiewirtschaftliche Tagesfragen 62/11: 90-92.

Lied, A. (2017): Studie zur Digitalisierung der Energiewirtschaft. München, Becker Büttner Held Consulting AG.

Maier, M. (2018): Metaanalyse: Digitalisierung der Energiewende. Renewable Energies Agency. www.unendlich-viel-energie.de/mediathek/ publikationen/metaanalyse-die-digitalisierung-der-energiewende

O'Sullivan, K. C./Howden-Chapman, P. L./Fougere, G. (2011): Making the connection: The relationship between fuel poverty, electricity disconnection, and prepayment metering. In: Energy Policy 39/2: 733-741.

Oschatz, B./Mailach, B. (2017): Kurzstudie Energieeinsparungen Digitale Heizung. Dresden, Institute for Building Systems Engineering Dresden.

Pohl, J./Höfner, A./Albers, E./Rohde, F. (2020): Nachhaltige Hard- und Software - für eine bessere (IT-)Welt. www.heise.de/hintergrund/MissingLink-Nachhaltige-Hard-und-Software-fuer-eine-bessere-IT-Welt-4851588. html

Prognos/Öko-Institut/Wuppertal-Institut (2020): Klimaneutrales Deutschland. Zusammenfassung im Auftrag von Agora Energiewende, Agora Verkehrswende und Stiftung Klimaneutralität. www.agora-energiewende. de/veroeffentlichungen/klimaneutrales-deutschland-zusammenfassung/

Reibling, N./Jutz, R. (2017): Energiearmut und Gesundheit. Die Bedeutung von Wohnbedingungen für die soziale Ungleichheit im Gesundheitszustand. In: Großmann, K., Schaffrin, A./Smigiel, C. (Eds.): Energie und soziale Ungleichheit. Wiesbaden, Springer VS. 157-184.

Sias, G.G. (2017): Characterization of the Life Cycle Environmental Impacts and Benefits of Smart Electric Meters and Consequences of their Deployment in California. Los Angeles, University of California.

UBA (2020): Erneuerbare Energien in Zahlen. www.umweltbundesamt.de/ themen/klima-energie/erneuerbare-energien/erneuerbare-energien-inzahlen

AUTHORS + CONTACT

Dr. Swantje Gährs, Dr. Astrid Aretz and Friederike Rohde are researchers at the Institut für ökologische Wirtschaftsforschung (IÖW). Institut für ökologische Wirtschaftsforschung (IÖW) Potsdamer Str. 105, 10785 Berlin. E-mail: swantje.gaehrs@ioew.de, astrid.aretz@ioew.de, friederike.rohde@ioew.de, Tel.: +49 308845940

Hendrik Zimmermann is an Energy Transition Researcher and Digital Transformation Policy Advisor at Germanwatch.

Germanwatch e. V., Stresemannstr. 72, 10963 Berlin. E-mail: zimmermann@germanwatch.org, Tel: +49 30288835672 